\title{
Working Digitally with Historical Maps
}

\section{By Humphrey Southall, guest editor}

This theme issue of the Journal of Map \& Geography Libraries contains papers presented at a workshop that I initiated, held at the New York Public Library on 26 February 2012 as part of the 2012 annual meeting of the Association of American Geographers. The main focus was not on digitizing maps but on what can be done with them once they have been digitized; and I am writing not as a map librarian but as a historical geographer seeking a wider role for historical maps in the increasingly digital humanities and heritage.

The last ten years have seen a "spatial turn" in the humanities, widely discussed (Goodchild and Janelle 2010; Wharf and Arias 2009; Withers 2009); the emergence of "digital humanities" as a distinct discipline, with new academic departments being established even in a time of general austerity (Schreiber, Siemens and Unsworth 2004; Cohen 2010); and, as an obviously related development, the emergence of historical GIS as a recognized sub-discipline (Bodenhamer, Corrigan and Harris, (editors) 2010; Jessop 2007). Taken together, these trends give a renewed emphasis to the "geography behind history"; to understanding social and cultural phenomena by placing historical events and processes, and the documents which record them, into a spatial framework. Further, these academic trends are paralleled in popular history by the growth of genealogy: "finding one's roots" is very much a geographical process, gaining economic significance through genealogy tourism.

However, historical maps and the map libraries that hold them have played a surprisingly small role in these developments. Historical GIS systems, whether built to support academic research or the more public presentation of historical content, have tended to geographically contextualize historical data and texts not with historical maps, but using essentially modern cartographic frameworks. A well known example of this is HistoryPin's global collection of crowd-sourced historical photographs (http://www.historypin.com), but they are far from alone 
in using Google Maps as a backcloth. Issues with the topographical accuracy of historical maps are only a partial explanation for the absence of historical maps from online historical geography. The development of substantial online map collections by volunteer networks of genealogists, despite an obvious lack of both technical and cartographic resources, shows a clear failure by map libraries to reach a large and hungry potential audience for their collections (Shular 2009); an example is Genmaps:

http://freepages.genealogy.rootsweb.ancestry.com/ genmaps

These papers included in this theme issue help make the argument that the basic business of map libraries should mostly move online, providing access to digital rather than paper copies. First, digital collections can include maps which could not be included in paper collections. Sweetkind-Singer's Project Ortelius was able to extend Stanford's online collection by scanning maps in private collections. Westington describes how over 38,000 maps images were made available online by the United States' Office of Coast Surveys, there having been no previous public access to the storage facility they charts and maps had accumulated in.

A second benefit of transitioning map libraries into the digital realm is the potential for creating catalogs far better suited to the needs of most map users. Simply moving a card catalog into an OPAC does not achieve this, as it is still searchable only through textual means by title, author, publisher, keywords, and the like: what most users want is a catalog searchable by location. This means that the catalog needs to hold the real-world coordinates of the area covered by each map. In addition to Westington's account, Knutzen shares how the New York Public Library has enabled their users to do this geo-referencing work online. The resulting catalogs are limited to single collections, so users still need to know which web sites are likely to hold maps of the area of interest. The February 2012 meeting also featured the first public presentation of the old Maps Online global search portal, which provides integrated access to many different online collections by location (Southall and Přidal 2012):

\section{http://www.oldmapsonline.org}


[Figure 1 near here]

A very obvious benefit of digitization is that it broadens access to map libraries and their collections since far more people have internet access than live near such a specialist map library. Web interfaces for viewing online maps have been revolutionized by AJAX-based tools enabling "slippy maps" without installing browser plug-ins. Google Maps is still the best known such interface, but OpenLayers and IIPImage now provide open source alternatives that can be implemented on top of a library's own collection. These provide a user interface to historical mapping that is easier to work with than manhandling very large sheets of paper, even if we see no benefit in eliminating wear-and-tear on priceless originals.

However, none of the papers here provide simple usage data, and indeed published analyses of digital map library usage seem to be extremely rare, despite the mass of statistics easily generated from web sites either from log analysis or the use of external services such as Google Analytics. The only such analysis found in all past issues of both this journal and e-Perimetron is Montaner and Roset (2010), which actually shows online access rapidly coming to dominate overall access; web visitors per month to the Catalan collection far exceeded numbers of on-site visits per year.

Rather than a librarian's perspective on actual usage of digitized historical maps, what we also have here are a series of perspectives from expert users. One central conclusion is that digitization at last enables library users to do what librarians have long-feared: shuffle sheets around in the collection, mix them up with other departments of the library and, still worse, cut them up and scribble on them. All can be seen here as researchers assemble different resources, cartographic and otherwise, to make sense of some small area. The two clearest examples of the expanse of usage that digitization allows are Leonard's study of Newtown Creek, which separates the New York boroughs of Queens and Brooklyn, and Fortin's study of the Don Valley within Toronto. Both projects made extensive use of fire insurance maps to document the evolution of these industrial zones and, especially for Newtown Creek, make sense of the modern- 
day patchwork of intensely polluted sites. The Don Valley Historical Mapping Project has created a public web site, at http://maps.library.utoronto.ca/dvhmp, but in both cases the richest jutaxposition of diverse sources is accessible only to those with GIS software. Copyright of some of the insurance maps is one constraint, but we also need more flexible and easily-usable software to present these resources to the general public in the areas being studied.

The papers by Hurley and Page have a similar focus, both covering a whole city, not industrial districts alone, and both specifically focused on Atlanta. Hurley writes from a librarian's perspective, including the project cataloguing and digitizing a large collection of planning maps from the mid-twentieth century that were then made available for teaching and research partly via the Google Maps interface. Page describes the construction of a very large historical GIS for the city from the maps, locating every manhole, starting with the digitization of a 1928 atlas of the city but also including much added textual information input using optical character recognition.

The relatively limited use of historical maps within historical GIS, noted above, is due in large part to the enormous amount of work required to convert from digital images of maps, even geo-referenced map images, to vector representations of the features on the maps. Most projects have found it far quicker to re-use and somehow back-date modern digital mapping which is already in vector form, but several papers here take on the demanding task of extracting feature information from historical maps. First, White describes such work by the Greater New Orleans Archaeology Program using paid staff and mainstream GIS software. Second Macdonald discusses a project which developed "crowd-sourcing" tools enabling online users to integrate historical mapping and street directories for Edinburgh, Scotland. Last, Marciano applies automation to the analysis of the "redlining" maps created by the United States Home Owners' Loan Corporation, using image processing software to convert colored zoning maps into polygons, city by city.

Finally, Edelson's MapScholar project, explicitly grounded in the spatial turn of the humanities, essentially bypasses map libraries, enabling individual scholars 
to create their own on-line map libraries, using public repositories like Flickr and Dropbox to store the images but then creating a superstructure through which researchers annotate and link their maps. Depending on commercial companies to maintain infrastructure in the really long term may prove problematic, but MapScholar has a potential to enable many more people to not merely look at old maps but engage with them creatively: given that any number of people can annotate or mash-up the same old map without damage, why should only map librarians and cartographic historians be so privileged, indeed, why should this be limited to "scholars" rather than, say, genealogists? Map libraries need to develop new infrastructures enabling "their" maps, rather than Google Maps, to be included within mash-ups on quite a few other web sites.

Three major obstacles need to be overcome if the full potential of digital map libraries are to be realized; and to some extent what follow are conclusions from the Old Maps Online project:

First, while Geographical Information Systems technology opens the door to many new ways of working with historical maps, off-the-shelf commercial GIS software can easily become an inappropriate straightjacket. One common consequence is web sites which contain historical maps but provide no URLs by which individual maps can be accessed: the site's URLs concern locations, and individual historical maps exist only as layers which can be made visible by onscreen controls when users happen to be at appropriate locations, and know which box to check. Another common outcome is on-line systems which offer no conventional textual searching at all. These problems often occur where the only advice on GIS available to librarians and archivists is from the local planning or urban development office with no experience of historical materials.

Second, in many libraries map librarians have little input into or sense of ownership of the library's web site: it is controlled by a separate digital library unit, or seen simply as a marketing function. This often became very clear when we asked map librarians why "their" URLs took the form they did, including the names of particular software packages, or asked them for web site usage data. One particularly unfortunate consequence is that even in libraries which have 
both geo-referenced parts of their digital map collections and exposed much of their metadata for automated harvesting the metadata do not include the georeferencing. The Old Maps Online project has worked closely with the David Rumsey Collection, who presented in New York but are not included here, and with the National Library of Scotland, and it is clear that these are not just unusually large digital map collections, but collections who see their web sites as their primary public face.

Third, copyright is inevitably a major issue. One obvious aspect is that, online, map libraries have been "disintermediated" as a source of modern topographic mapping: where mapping agencies have not made their work directly available online, advertising-supported web sites like Bing and Google Maps have taken over, and even the largest individual libraries lack the resources to seriously compete. The practical challenges to map libraries are arguably rather different. On the one hand, many user needs for "old maps" concern not antique mapping but the fairly recent past: neither Google nor mapping agencies show much interest in mapping from ten or twenty years ago, but in many countries maps from even fifty years ago cannot be scanned and made available on-line by libraries because the maps remain within the original copyright; so they are available nowhere. On the other hand, libraries themselves are often highly restrictive in how "their" digital mapping may be used, and this often makes little commercial sense: if maps can be exposed for online viewing, why can't they be used in geo-spatial mash-ups? And why are libraries so nervous about publishing their catalog information under Creative Commons licenses, enabling it to be used by portals like Old Maps Online without special negotiations, when almost the only use is to drive more visitors to the library sites?

Even with these challenges, these are exciting times for both digital and print map libraries. The papers assembled here cover activities far more diverse than scanning maps and putting them on web sites. They point to a future where historical maps continue to exist in both public and private collections but are also available digitally to a vast and geographically dispersed audience, becoming the focal point of a wide variety of both scholarly and popular activity. The content of the Working Digitally with Historical Maps special program, 
including some presentations not represented in this theme issue, represent a resurgence of place-based and text-based research that will greatly enhance the world we live in and change with.

\section{Acknowledgments}

Matt Knutzen of the New York Public Library and Lex Berman of Harvard's Center for Geographic Analysis co-organized the workshop, which was sponsored by Cartography Associates and the New York Public Library. Thanks to JMGL editors for comments on an earlier draft.

\section{References}

Bodenhamer, David J., John Corrigan and Trevor Harris, editors. 2010. The Spatial Humanities: GIS and the future of humanities scholarship. Indiana University Press.

Cohen, Patricia. 2010. Digital Keys for Unlocking the Humanities' Riches. New York Times, $17^{\text {th }}$ November 2010.

(http://www.nytimes.com/2010/11/17/arts/17digital.html)

Goodchild, Michael and Donald Janelle. 2010. Toward critical spatial thinking in the social sciences and humanities. Geojournal 75, no. 1: 3-13.

Jessop, Martyn. 2007. The inhibition of geographical information in digital humanities scholarship. Literary and Linguistic Computing 23, no. 1 (November 2007): 39-50.

Montaner, Carme and Rafael Roset. 2010. Impact of the internet users on the Map Library of Catalonia access collections. e-Perimetron 5, no. 2: 88-96.

Schreiber, Susan, Ray Siemens and John Unsworth. 2004. A Companion to Digital Humanities. Malden, MA: Blackwell.

Shular, Michele. 2009. Turning Genealogists onto GIS. Journal of Map \& Geography Libraries 5, no. 1: 55-71. 
Southall, Humphrey, and Petr Přidal. 2012. Old Maps Online: Enabling global access to historical mapping. e-Perimetron 7, no. 2: 73-81.

Wharf, Barney, and Santa Arias. 2009. The Spatial Turn: Interdisciplinary perspectives. Abingdon, New York: Routledge.

Withers, Charles. 2009. Place and the "spatial turn" in geography and in history. Journal of the History of Ideas 70, no. 4 (October 2009): 637-658. 


\section{Figure 1: The Old Maps Online federated search portal for historical maps}

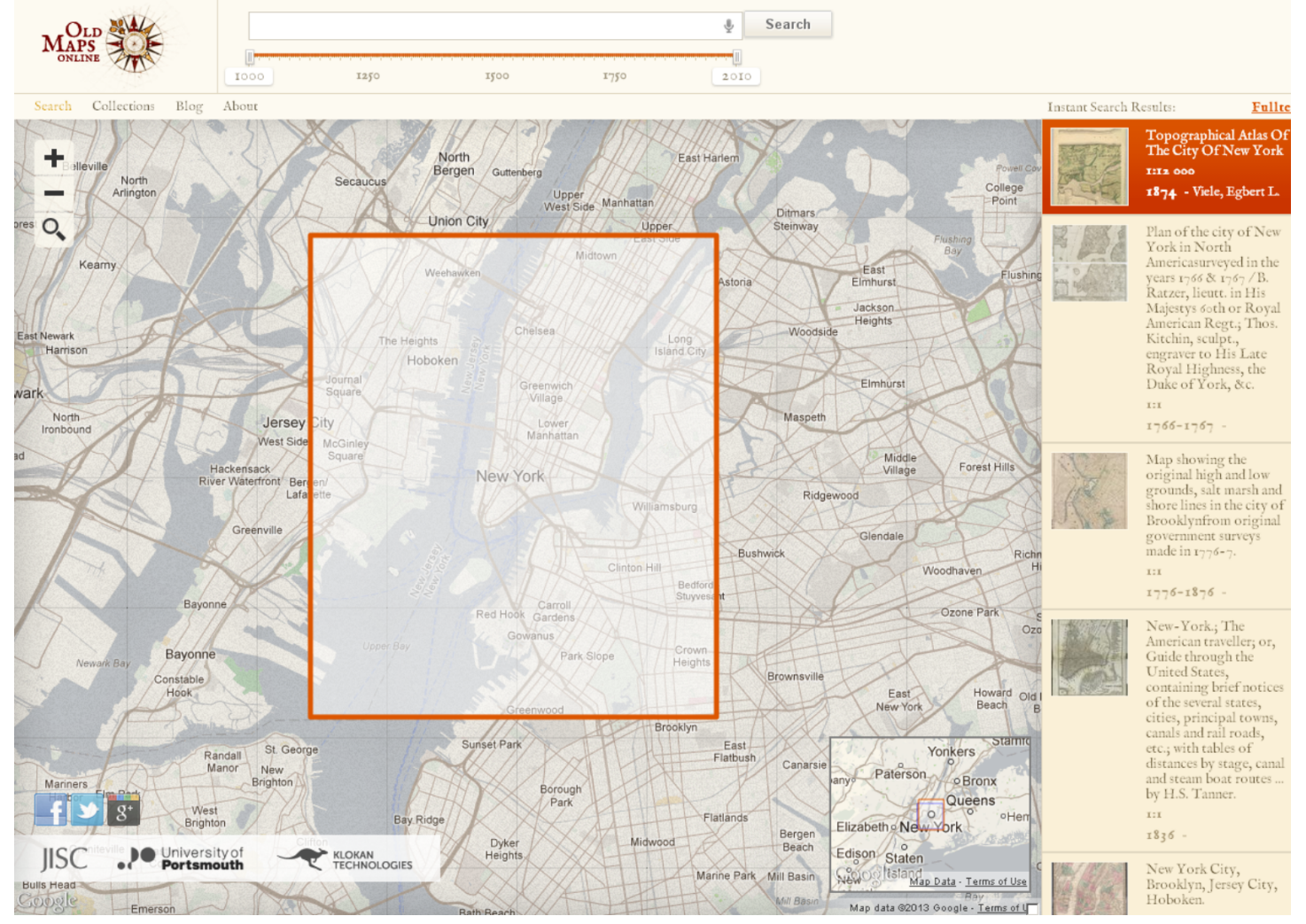

Old Maps Online was launched at the "Working Digitally" meeting in New York in February 2013 as a global search portal for maps in many different online libraries, and the view above shows the portal centered on the New York Public Library itself. It uses the MapRank Search interface developed by Klokan Technologies Gmbh and already used by, for example, the David Rumsey Collection, but scaled up to handle hundreds of thousands of maps. Searching is primarily by location and, using the timeline bar at the top, date; so maps must be not just directly accessible online but geo-referenced. The Boston Public Library report that, since contributing their metadata, Old Maps Online has become their largest single source of online referrals, “topping Google, Facebook, Wikipedia, and our own institution's website”; libraries wanting to be included should contactinfo@oldmapsonline.org. 